\title{
Probing into the Interaction of Nicotine and Bovine Submaxillary Mucin: NMR, Fluorescence, and FTIR Approaches
}

\author{
Xiaoxiang Liao, ${ }^{1,2}$ Dalin Yuan, ${ }^{2}$ Jianguo Tang, ${ }^{2}$ Hongqin Yang, ${ }^{1}$ Bing Liang, \\ Qiang Cheng, ${ }^{1}$ and Hui $\mathrm{Li}^{1}$ \\ ${ }^{1}$ College of Chemical Engineering, Sichuan University, Chengdu, Sichuan 610065, China \\ ${ }^{2}$ Technology Center, China Tobacco Yunnan Industrial Co., Ltd., Kunming, Yunnan 650204, China
}

Correspondence should be addressed to Jianguo Tang; jgtang@163.com and Hui Li; lihuilab@sina.com

Received 13 December 2015; Revised 16 January 2016; Accepted 28 January 2016

Academic Editor: Rizwan Hasan Khan

Copyright (C) 2016 Xiaoxiang Liao et al. This is an open access article distributed under the Creative Commons Attribution License, which permits unrestricted use, distribution, and reproduction in any medium, provided the original work is properly cited.

Nicotine, the important component of cigarette products, may have an impact on the oral environment after inhalation. The research of interaction between nicotine and bovine submaxillary mucin (BSM) contributes to understand the binding mechanism of nicotine and BSM, and the effects of nicotine on the structure and function of the mucin. NMR data demonstrated that the interaction between nicotine and BSM did exist, and it was pyrrolidyl ring of nicotine playing the major role in the binding. The quenching mechanisms of nicotine and BSM in different $\mathrm{pH}$ were different: for acidic environment, the quenching was dynamic; while it became static in the alkaline circumstance. Synchronous fluorescence spectra indicated that nicotine had effect on the microenvironment of the Trp rather than Tyr residue. Meanwhile, the impact of nicotine on the conformation of BSM was also confirmed by 3D fluorescence and FTIR spectra.

\section{Introduction}

Mucins are large, abundant, and filamentous glycoproteins and composed of secreted mucins and cell-tethered mucins with polymerizing and nonpolymerizing forms $[1,2]$. General structural features of mucins consist of a long central domain rich in proline, threonine, and serine (PTS domain) and are densely grafted with anionic and hydrophilic carbohydrate chains [3]. Mucins can act as a steric barrier, preventing nonspecific interaction of proteins and cells with the underlying cell membrane, protecting underlying tissues against external insult, mechanical stress, and pathogens, transducing cell signal, and so forth $[4,5]$.

Salivary mucin, a kind of salivary protein, accompanies with the whole digestive process from the oral to gastrointestinal organs and plays a significant role in the protection of oral cavity $[6,7]$. Submaxillary mucin is the most associated mucin types in oral processing [5]. For BSM, the glycosylation level of the PTS domain is about $70-85 \%$ of the total molecular weight and sialic acid accounts for as much as $30 \%$ of the molecular weight [3]. As one of the mucins, BSM contains many charged groups, resulting in its $\mathrm{pH}$-dependent physicochemical properties. Moreover, BSM is amphiphilic and can be linked with each other or interact with other proteins via noncovalent bonds $[8,9]$. However, the field of investigating the interaction between BSM and small molecules is still blank.

Tobacco smoking is a major worldwide health problem, which can lead to high morbidity and mortality. As the principal psychoactive agent in tobacco, nicotine (NIC, shown in Figure 1) has been determined to be a highly addictive substance with subjective effects like clear-headedness, feelings of relief, fatigue recovery, and hyperactivity $[10$, 11]. During cigarette smoking, NIC is absorbed into the body and induces multiple pharmacological and toxicological effects [12]. Thus, NIC may have an effect on the activities of the oral cavity, such as salivary mucin, after its inhalation, which may pose a further threat to animal's health. However, the interaction between NIC and BSM has not been studied so far. 


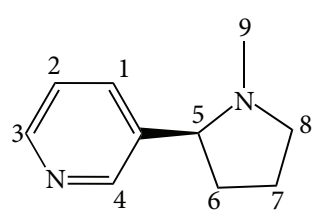

Figure 1: Molecular structure of NIC.

This study was committed to probe into the interaction of NIC with BSM in vitro by spectral approaches. Nuclear magnetic resonance (NMR) measurements were carried out to investigate whether and how the interaction between BSM and NIC occurred. Fluorescence quenching measurements were used for obtaining the quenching mechanism. Due to the influence of $\mathrm{pH}$ on the forms of NIC in the solution, the effects of $\mathrm{pH}$ on the binding of NIC to BSM were discussed. Synchronous fluorescence, three-dimensional (3D) fluorescence, and Fourier transform infrared (FTIR) spectra were used to analyze the effect of NIC on the conformation of BSM.

\section{Experimental}

2.1. Chemicals and Materials. Bovine submaxillary mucin (BSM) was purchased from Dalian Meilun Biological Technology Co., Ltd. (Dalian, China). The contents of protein and carbohydrate were $36.6 \%$ and $56.7 \%$, respectively. The BSM stock solution was prepared at a concentration of $4.76 \times$ $10^{-4} \mathrm{M}$ in $0.05 \mathrm{M}$ phosphate buffer. Nicotine (NIC) (purity > 99\%) and deuterium oxide at $99.9 \%$ purity were provided by J\&K Scientific, Ltd. (Beijing, China). All other reagents were of analytical grade.

\subsection{Methods}

2.2.1. NMR Measurements. ${ }^{1} \mathrm{H}$ NMR spectra experiments were performed on a Bruker Avance $400 \mathrm{MHz}$ NMR spectrometer operating at $400.13 \mathrm{MHz}$ for hydrogen at $298 \mathrm{~K}$. The NMR studies were carried out by fixing the concentration of NIC $\left(9.00 \times 10^{-3} \mathrm{M}\right)$ while adding different ratios of BSM $(r=[\mathrm{BSM}] /[\mathrm{NIC}]=0,1 / 400,1 / 200,1 / 100,1 / 50)$.

2.2.2. Fluorescence Measurements. Fluorescence quenching measurements were conducted via a Cary Eclipse Fluorescence Spectrophotometer (Varian, USA) equipped with $1.0 \mathrm{~cm}$ quartz cells. Fluorescence quenching spectra were recorded by fixing the concentration of BSM $\left(1.10 \times 10^{-4} \mathrm{M}\right)$ while varying the NIC concentration from 0.00 to $19.15 \times$ $10^{-3} \mathrm{M}$ at three $\mathrm{pH}(5.0,6.9$, and 8.0). Prior to fluorescence measurements, the solutions were mixed and maintained for $1 \mathrm{~h}$ in a thermostat water bath at 288,298 , and $310 \mathrm{~K}$.

Synchronous fluorescence spectra of BSM $\left(1.10 \times 10^{-4} \mathrm{M}\right)$ with different NIC concentrations $\left(0-19.15 \times 10^{-3} \mathrm{M}\right)$ were measured at $\Delta \lambda=15 \mathrm{~nm}$ and $\Delta \lambda=60 \mathrm{~nm}$, respectively.

Three-dimensional (3D) fluorescence spectra of BSM $\left(1.10 \times 10^{-4} \mathrm{M}\right)$ and NIC-BSM complex (molar ratio, $1: 1)$ were obtained at an excitation wavelength range of

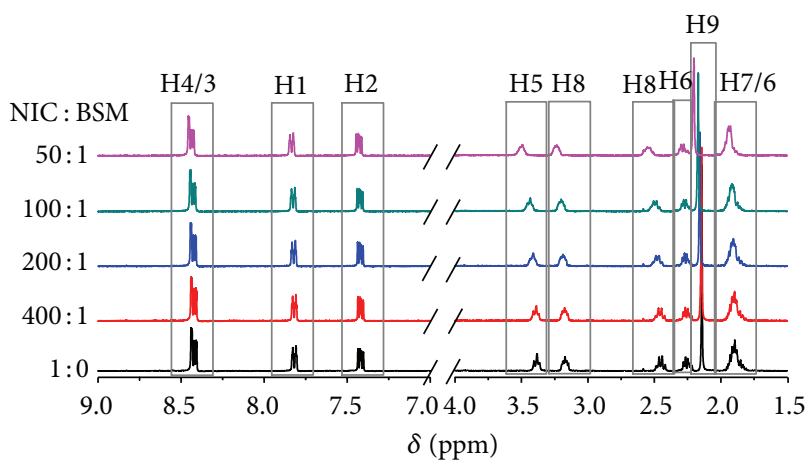

FIgURE 2: ${ }^{1} \mathrm{H}$ NMR spectra of NIC $\left(9.00 \times 10^{-3} \mathrm{M}\right)$ in the absence and presence of BSM $(r=[\mathrm{BSM}] /[\mathrm{NIC}]=0,1 / 400,1 / 200,1 / 100$, $1 / 50)$ at $298 \mathrm{~K}$.

200-400 $\mathrm{nm}$ with an increment of $5 \mathrm{~nm}$. Emission spectra were also monitored between 200 and $500 \mathrm{~nm}$.

2.2.3. FTIR Measurements. FTIR spectra were recorded on a Nicolet-6700 FTIR (Thermo, USA) spectrometer with a smart OMNI-sampler accessory. The spectra of BSM $(9.52 \times$ $\left.10^{-5} \mathrm{M}\right)$ in the absence and presence of NIC $\left(2.49 \times 10^{-4} \mathrm{M}\right)$ were recorded over the spectral range $4000-600 \mathrm{~cm}^{-1}$ with a resolution of $4 \mathrm{~cm}^{-1}$ and 64 scans at $298 \mathrm{~K}$. Background spectra were collected before each measurement. The spectrum of the buffer solution was subtracted from the spectra of the BSM and the BSM-NIC complexes.

\section{Results and Discussion}

\subsection{Characterization of Interaction between BSM and NIC}

3.1.1. NMR Spectra Analysis. NMR spectrum, an effective method for evaluating the interaction between a ligand and its target molecule $[13,14]$, was conducted to study whether and how NIC bound to BSM. The changes of NMR parameters of ligands, such as absolute peak positions and linewidth, can reflect the binding activity between protein and ligand [15]. As displayed in Figure 2, different degrees of changes in peak position as well as the overlapping of split peaks were noticed with increasing BSM, indicating that the molecular interaction of NIC with BSM occurred.

To present the changes in chemical shift of different protons for NIC more intuitively, the changes of the chemical shift $(\Delta \delta)$ were calculated and plotted versus the molar ratio of BSM to NIC (Figure 3). Compared with the protons on the pyridine ring of NIC, the changes of chemical shifts for protons ( $\mathrm{H} 5, \mathrm{H} 6, \mathrm{H} 7, \mathrm{H} 8$, and $\mathrm{H} 9)$ on the pyrrolidyl ring of NIC were much more obvious under the same condition, illustrating the pyrrolidyl ring of NIC played a more important role in the NIC-BSM complex formation. In conclusion, NIC, pyrrolidyl ring of NIC more particular, was capable of interacting with BSM.

3.1.2. Fluorescence Quenching and Quenching Mechanism. On the basis of NMR studies, the fluorescence quenching of BSM-NIC system was studied. In order to simulate the oral 


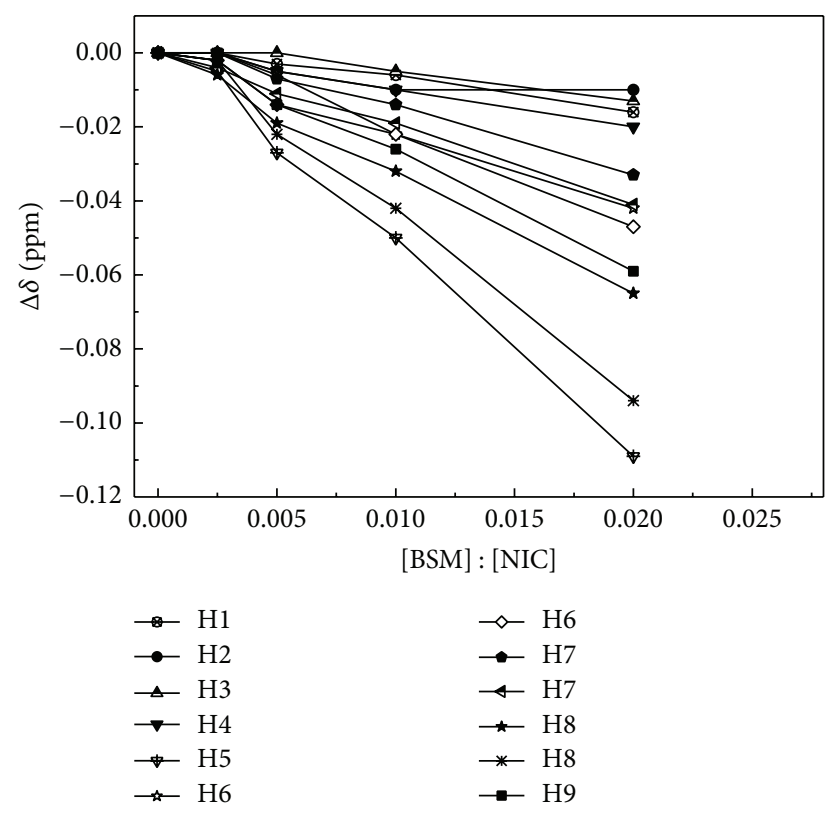

FIGURE 3: Change in chemical shift $(\Delta \delta)$ versus the molar ratio of BSM to NIC. $T=298 \mathrm{~K}$.

environment of animal, fluorescence quenching experiments were carried out at $310 \mathrm{~K}$ and $\mathrm{pH} 6.9$, and the results were displayed in Figure 4(b2). As seen in Figure 4(b2), BSM can emit strong fluorescence after being excited with wavelengths of $280 \mathrm{~nm}$. The fluorescence intensity decreased significantly with the addition of NIC, which suggested that NIC could interact with BSM [16]. In addition to the change in intensity, the maximum emission wavelength was slightly red shifted, suggesting that the conformational changes in BSM were induced by NIC $[17,18]$.

Generally, fluorescence quenching may be either dynamic, which is caused by the collision of fluorophore with quencher, or static, which is caused by the formation of ground-state complex $[19,20]$. As temperature rising, dynamic quenching constants are expected to increase because higher temperature results in larger diffusion coefficients. Reversely, the static quenching constants are supposed to decrease because the complex stability decreases with increasing temperature [21]. Thus, these two mechanisms could be distinguished by comparing the changes of quenching constants with temperature rising. The quenching constants could be estimated by the following well-known Stern-Volmer equation $[22,23]$ :

$$
\frac{F_{o}}{F}=K_{\mathrm{SV}}[Q]+1=K_{q} \tau_{0}[Q]+1,
$$

where $F_{o}$ and $F$ denote the fluorescence intensities of BSM in the absence and presence of NIC, respectively. [Q] is the concentration of the quencher, and $K_{\mathrm{SV}}$ is the quenching constant. $\tau_{0}$ is the fluorescence lifetime of the molecule without any quencher and the fluorescence lifetime of the biopolymer is about $10^{-8} \mathrm{~s}$ [24]. $K_{q}$ is the quenching rate constant of the biological macromolecule.
TABLE 1: Stern-Volmer $K_{\mathrm{SV}}$ at different temperatures as well as at different values of $\mathrm{pH}$.

\begin{tabular}{cccc}
\hline $\mathrm{pH}$ & $T(\mathrm{~K})$ & $K_{\mathrm{SV}}\left(\mathrm{M}^{-1}\right)$ & $K_{q}\left(\times 10^{9}\right)$ \\
\hline \multirow{3}{*}{5.0} & 288 & 13.67 & 1.37 \\
& 298 & 18.21 & 1.82 \\
& 310 & 20.08 & 2.01 \\
\hline \multirow{3}{*}{6.9} & 288 & 15.76 & 1.58 \\
& 298 & 17.83 & 1.78 \\
& 310 & 18.46 & 1.85 \\
\hline \multirow{3}{*}{8.0} & 288 & 28.17 & 2.82 \\
& 298 & 27.59 & 2.76 \\
& 310 & 25.34 & 2.53 \\
\hline
\end{tabular}

The linear regressions of the plot of $F_{o} / F$ against [Q] at different temperatures were shown in Figure 4(b2), and the corresponding values of $K_{\mathrm{SV}}$ and $K_{q}$ were listed in Table 1 . $K_{\mathrm{SV}}$ increased as the temperature rising, illustrating that the interaction was dynamic and driven by collision.

3.1.3. Binding Constants and Thermodynamic Parameters. The binding constants $(K)$ and number of binding sites $(n)$ could be calculated by the following equation [25]:

$$
\log \left[\frac{\left(F_{o}-F\right)}{F}\right]=\log K+n \log [Q],
$$

where $F_{o}$ and $F$ demonstrate the fluorescence intensities in the absence and presence of BSM, respectively, and [Q] refers to the concentration of BSM. $K$ and $n$, determined by the linear regression of the plot of $\log \left[\left(F_{o}-F\right) / F\right]$ against $\log [Q]$, are the binding constants and number of binding sites, respectively. The results were listed in Table 2. The binding constants and number of binding sites increase with the temperature rising, which indicated that temperature had an impact on the binding of NIC to BSM.

Thermodynamic parameters $(\Delta H, \Delta S$, and $\Delta G)$ can be calculated using the data of the fluorescence quenching measurements and by the van't Hoff equation as follows [26]:

$$
\begin{aligned}
\ln K & =-\frac{\Delta H}{R T}+\frac{\Delta S}{R} \\
\Delta G & =\Delta H-T \Delta S=-R T \ln K,
\end{aligned}
$$

where $K$ is the associative binding constant at the corresponding temperature and $R$ is the gas constant.

As shown in Table 2, $\Delta G$ was negative, suggesting that the binding was spontaneous. Meanwhile, according to the theory of Ross and Subramanian [27], the positive values of $\Delta H$ and $\Delta S$ illustrated that the hydrophobic force played a major role in the binding process.

3.1.4. The Effects of $p H$ on the Fluorescence Quenching of BSM by NIC. NIC is a weak base with different forms in different $\mathrm{pH}$ [28], which may cause differences in the binding of NIC to $\mathrm{BSM}$ under the conditions of different $\mathrm{pH}$. Besides, there are 
TABLE 2: The binding constant $(K)$, number of sites $(n)$, and thermodynamic parameters at different temperatures.

\begin{tabular}{lccccc}
\hline$T / K$ & $K\left(\mathrm{M}^{-1}\right)$ & $n$ & $\Delta G\left(\mathrm{KJ} \cdot \mathrm{mol}^{-1}\right)$ & $\Delta H\left(\mathrm{KJ} \cdot \mathrm{mol}^{-1}\right)$ & $\Delta S\left(\mathrm{~J} \cdot \mathrm{mol}^{-1} \cdot \mathrm{K}^{-1}\right)$ \\
\hline 288 & 13.61 & 0.991 & -62.03 & 55.61 & 215.58 \\
298 & 38.82 & 1.195 & -64.19 & & \\
310 & 74.45 & 1.302 & -66.77 & & \\
\hline
\end{tabular}
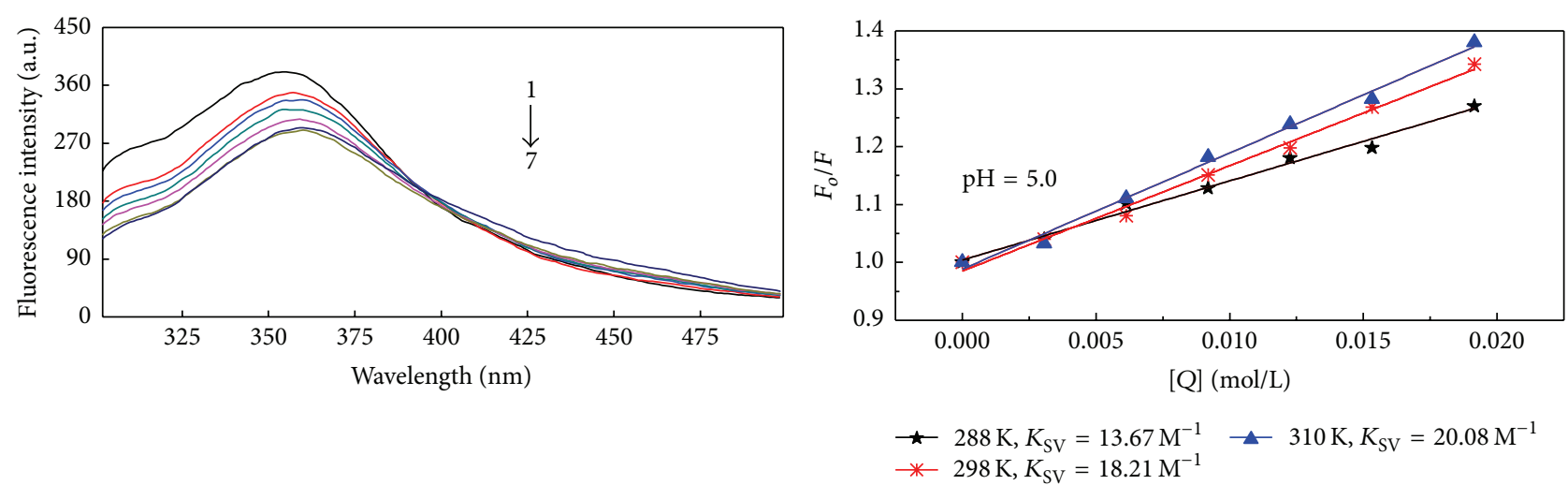

(a1)

(a2)
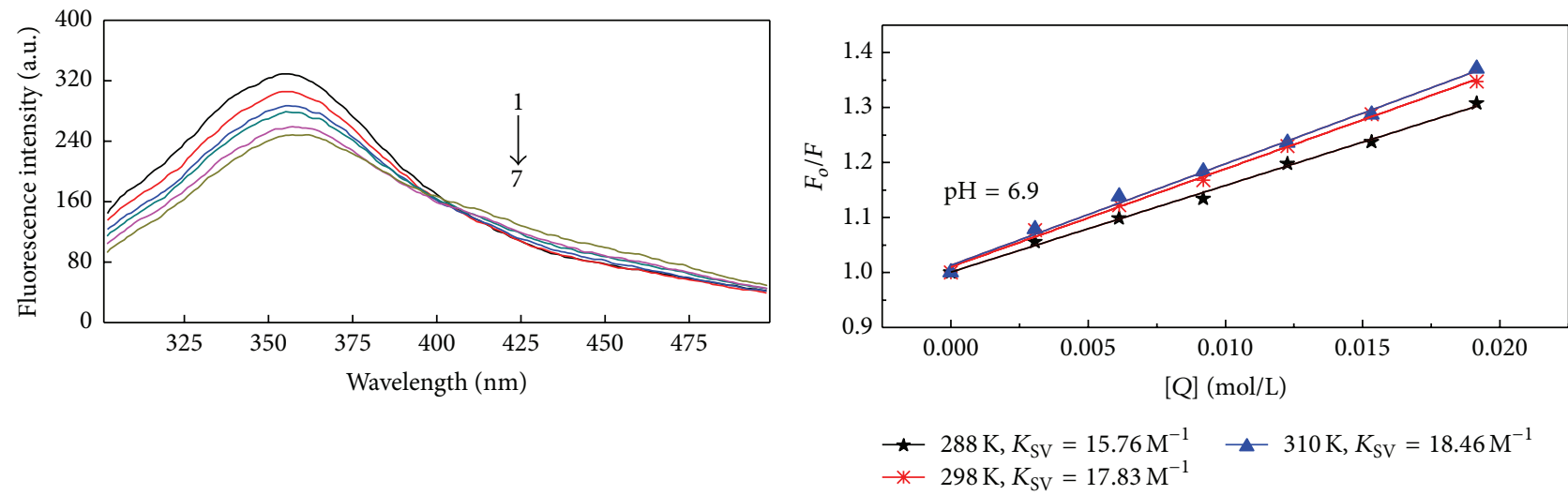

(b1)

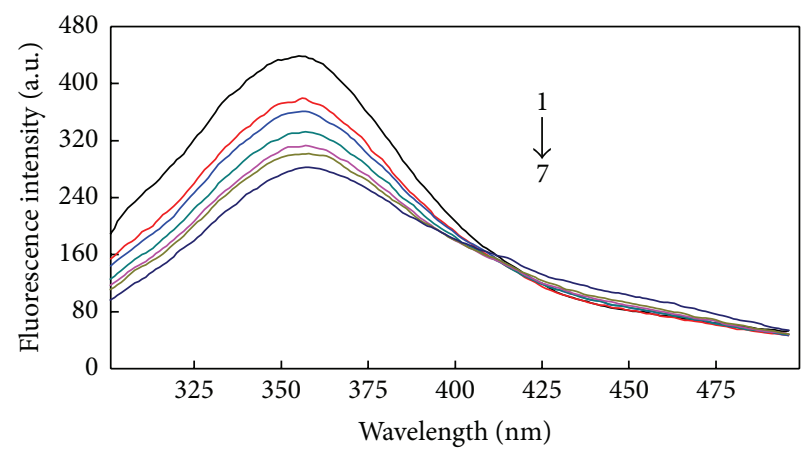

(b2)

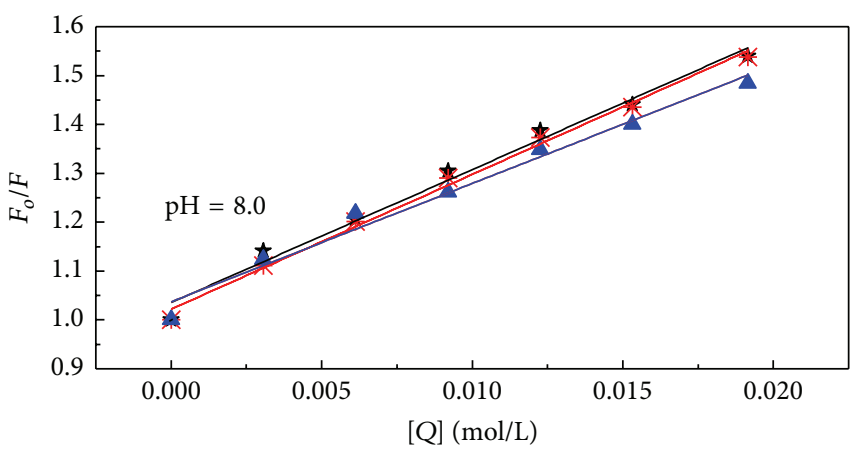

$\star 288 \mathrm{~K}, K_{\mathrm{SV}}=28.17 \mathrm{M}^{-1}$
$* 298 \mathrm{~K}, K_{\mathrm{SV}}=27.59 \mathrm{M}^{-1}$

$\neg 310 \mathrm{~K}, K_{\mathrm{SV}}=25.34 \mathrm{M}^{-1}$

(c1)

(c2)

FIGURE 4: Fluorescence emission spectra of BSM $\left(C_{\mathrm{BSM}}=1.10 \times 10^{-4} \mathrm{M}\right)$ in presence of NIC $\left(C_{\mathrm{NIC}}=0-19.15 \times 10^{-3} \mathrm{M}\right)$ at $\mathrm{pH}=5.0,6.9,8.0(\mathrm{al}$, b1, and c1). The Stern-Volmer plots for BSM-NIC interaction (a2, b2, and c2) at 288, 298, and $310 \mathrm{~K}$. 


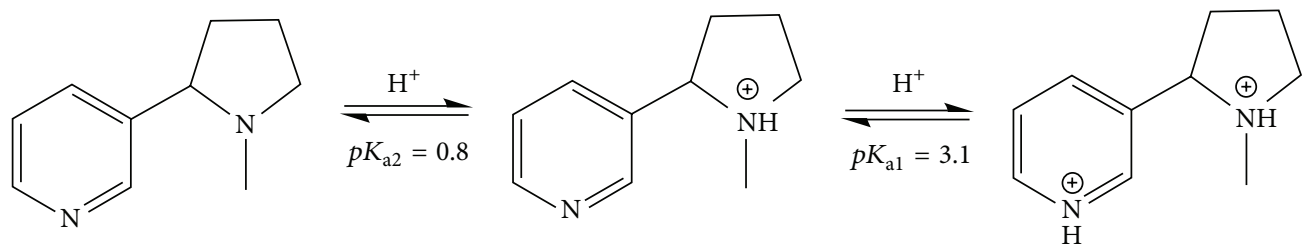

FIGURE 5: Structural formula of free NIC and its protonated forms.

differences in $\mathrm{pH}$ of individual oral environment. Therefore, the effects of $\mathrm{pH}$ on the interaction of NIC to BSM are valuable to be investigated. In addition to the above $\mathrm{pH}(\mathrm{pH}$ 6.9), the fluorescence quenching in $\mathrm{pH} 5.0$ and $\mathrm{pH} 8.0$ was also investigated. All the results were summarized in Figure 4 and Table 1.

As shown in Table 1 , the quenching mechanism in $\mathrm{pH}$ 5.0 was similar to that in $\mathrm{pH} 6.9$; namely, it was dynamic under the condition of acidity. While it was opposite under alkaline condition ( $\mathrm{pH} 8.0), K_{\mathrm{SV}}$ decreased with increasing of the temperature; that is to say, the quenching was static along with the formation of ground-state complex. Besides, the larger $K_{\mathrm{SV}}$ in alkaline condition showed that the binding of NIC to BSM was stronger in alkaline environment. Putting it another way, the content of NIC in the cigarettes for people who are in more alkaline oral environment should be lower.

The different mechanisms and quenching ability may be due to the different forms of NIC and BSM in different values of $\mathrm{pH}$. As mentioned above, NIC which is a binary organic weak base satisfied the following equilibrium $\left(p K_{\mathrm{a} 1}=\right.$ 3.1, $\left.p K_{\mathrm{a} 2}=8.0\right)[28]$.

The forms of NIC in the acid and alkaline condition are different: $\mathrm{C}_{10} \mathrm{H}_{14} \mathrm{~N}_{2} \mathrm{H}_{2}{ }^{2+}$ in acid, and $\mathrm{C}_{10} \mathrm{H}_{14} \mathrm{~N}_{2}$ as well as $\mathrm{C}_{10} \mathrm{H}_{14} \mathrm{~N}_{2} \mathrm{H}^{+}$in alkaline, as shown in Figure 5. Thus, when $\mathrm{pH}$ reaches to 5 , NIC is in the form of $\mathrm{C}_{10} \mathrm{H}_{14} \mathrm{~N}_{2} \mathrm{H}_{2}{ }^{2+}$, while $\mathrm{BSM}$ is near to its isoelectric point with relatively tight structure and the aromatic amino acid residues which contributed to the fluorescence are mainly in hydrophobic region. NIC with a strong positive charge is equivalent to the molecular ion, which will limit its access to the hydrophobic region; thereby the opportunity to interact with the aromatic amino acid residues in the hydrophobic region will be reduced. However, when $\mathrm{pH}>7$, more amino acid residues are exposed to the surface of BSM and the solution, and the positive charges of NIC are decreased to be more neutral, which will strengthen the interaction between NIC and BSM, as well as the formation of complex.

\subsection{Conformation Investigations}

3.2.1. Synchronous Fluorescence Measurements. Synchronous fluorescence spectroscopy is a very simple, sensitive, and effective technique to probe into the microenvironment of amino acids residues of protein, and it can be obtained by setting a fixed interval $(\Delta \lambda)$ between the excitation and emission monochromator [29]. Specifically, when the scanning interval $(\Delta \lambda)$ is set to $15 \mathrm{~nm}$ and $60 \mathrm{~nm}$, the synchronous

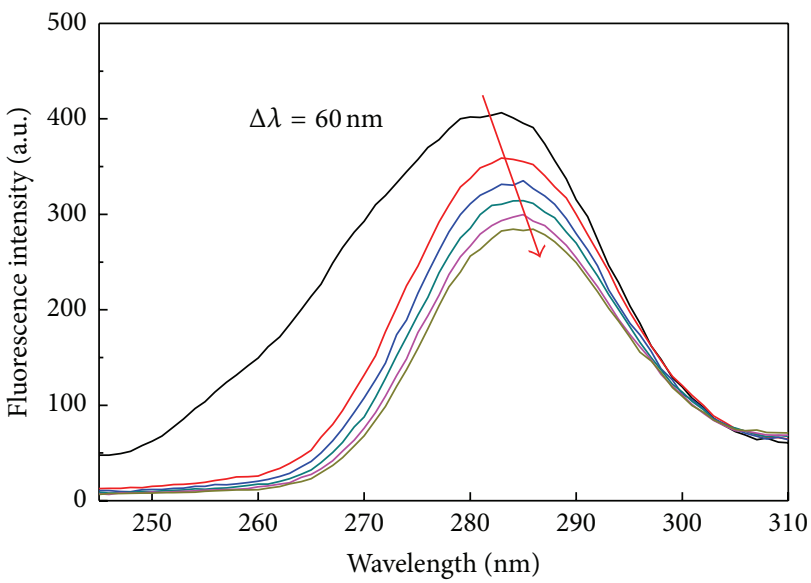

FIGURE 6: Synchronous fluorescence spectra of BSM $\left(C_{\mathrm{BSM}}=1.10 \times\right.$ $\left.10^{-4} \mathrm{M}\right)$ in different NIC concentrations: $C_{\mathrm{NIC}}=0-19.15 \times 10^{-3} \mathrm{M}$ (from top to bottom). $\Delta \lambda=60 \mathrm{~nm}\left(T=298 \mathrm{~K}\right.$, slit width: $E_{x}=$ $\left.E_{m}=10 \mathrm{~nm}\right)$.

fluorescence gives the characteristic information of tyrosine (Tyr) and tryptophan (Trp) residues, respectively [30]. There was a slight emission wavelength at $\Delta \lambda=15 \mathrm{~nm}$ (data not show), indicating the emission of BSM is primarily attributed to the Trp residues. The effect of NIC on BSM synchronous fluorescence $(\Delta \lambda=60 \mathrm{~nm})$ was displayed in Figure 6. The maximum emission wavelength shows a gradual red shift with the addition of NIC, which demonstrated the polarity around the Trp residue was slightly changed to be more polar in the presence of NIC [31]. Besides, the decrease of fluorescence intensity could also be observed in Figure 6, which further indicates the occurrence of fluorescence quenching during the binding process. Moreover, the decrease of fluorescence intensity might due to the reduction of energy transfer between aromatic amino acid residues, resulting from the stretch of BSM caused by high concentration of NIC.

3.2.2. 3D Fluorescence Spectra. 3D fluorescence spectrometry, a new method for the study of protein conformation, was also used to investigate the structural changes in BSM caused by interaction with NIC. The 3D fluorescence spectra of BSM in the absence and presence of NIC were shown in Figure 7, and the corresponding data were summarized in Table 3. Peak 1 refers to the spectral characteristic of Trp and Tyr residues, and peak 2 presents the fluorescence characteristics of the polypeptide backbone structures and is relevant to the secondary structure of protein $[32,33]$. 


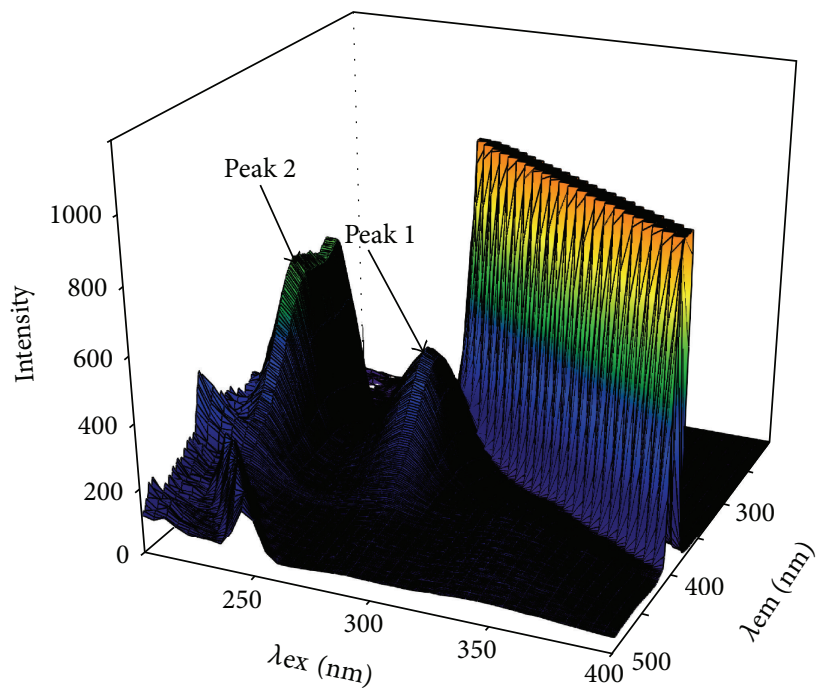

(a)

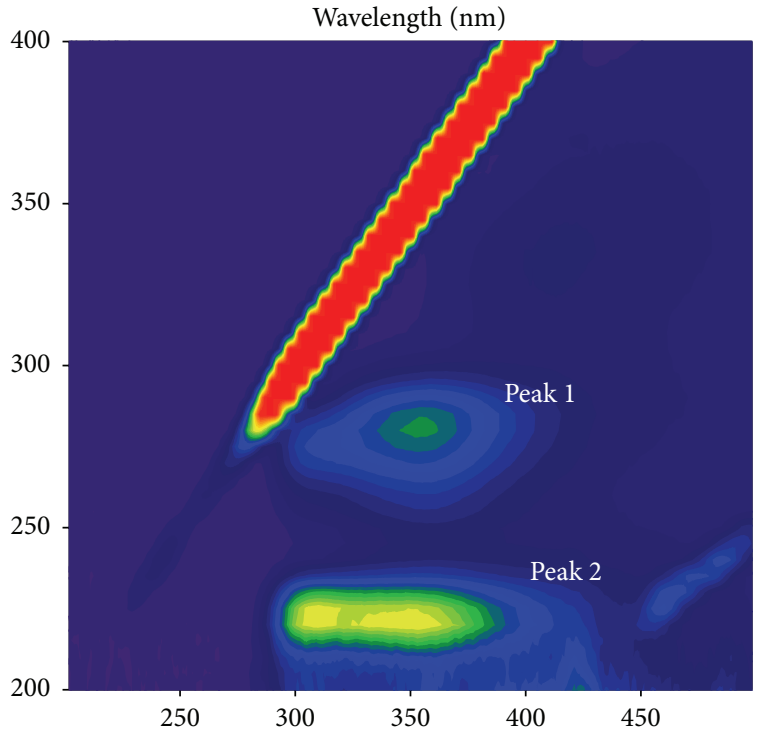

(c)

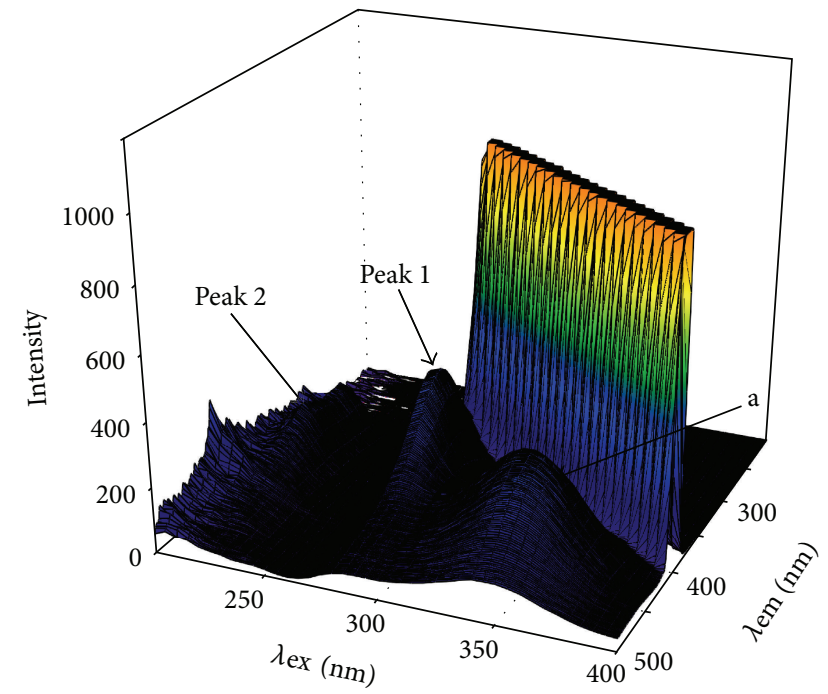

(b)

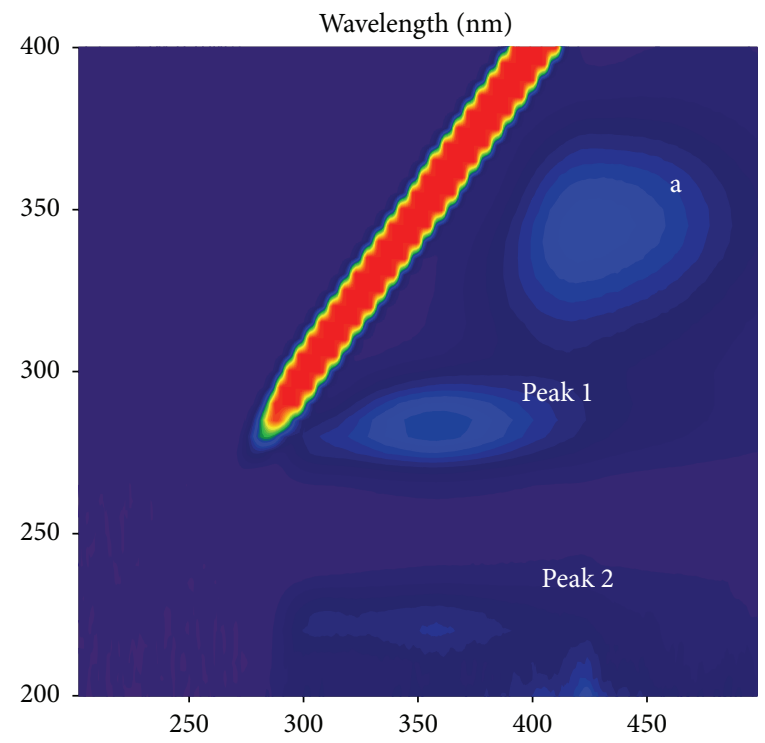

(d)

FIGURE 7: 3D fluorescence spectra of BSM (a) and BSM-NIC system (b). Contour spectra of BSM (c) and BSM-NIC system $(\mathrm{d}) . C_{\mathrm{BSM}}=2 \cdot 20 \times$ $10^{-4} \mathrm{M}, C_{\mathrm{NIC}}=0.61 \times 10^{-2} \mathrm{M}$.

TABLE 3: 3D fluorescence spectral parameters BSM and BSM-NIC system.

\begin{tabular}{lcccc}
\hline System & Peak number & $\begin{array}{c}\text { Peak position } \\
\lambda \mathrm{ex} / \lambda \mathrm{em}(\mathrm{nm} / \mathrm{nm})\end{array}$ & $\begin{array}{c}\text { Stokes shift } \\
\Delta \lambda(\mathrm{nm})\end{array}$ & Intensity \\
\hline \multirow{2}{*}{ BSM } & 1 & $280 / 352$ & 72 & 457 \\
& 2 & $230 / 348$ & 118 & 468 \\
\hline \multirow{2}{*}{ BSM-NIC } & 1 & $280 / 358$ & 78 & 384 \\
& 2 & $230 / 352$ & 122 & 131 \\
\hline
\end{tabular}

When NIC was added, a decrease in intensity along with a slight red shift of the maximum emission wavelength in peaks 1 and 2 occurred. Moreover, a new fluorescence peak, named peak a, appeared, which was considered as the fluorescence peak of free NIC with high concentration. Owing to the intensity changes and peak shifts, the conclusions could be drawn that the binding of NIC to BSM induced conformational and microenvironmental changes of BSM [34]. And these findings were basically in agreement with the results of synchronous fluorescence measurements.

3.2.3. FTIR Spectra. FTIR has emerged as a widely used and efficient method to analyze the structural and conformational changes of protein after interacting with small molecules [35]. The stability of protein secondary structure is closely related to the formation of hydrogen bonds. Once the hydrogen bonds in the protein molecules are influenced by the external 


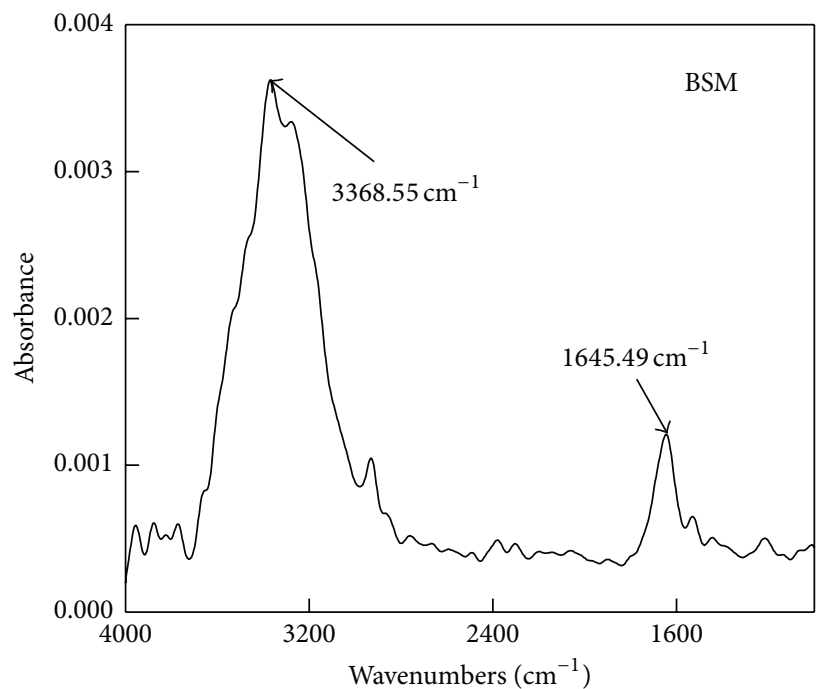

(a)

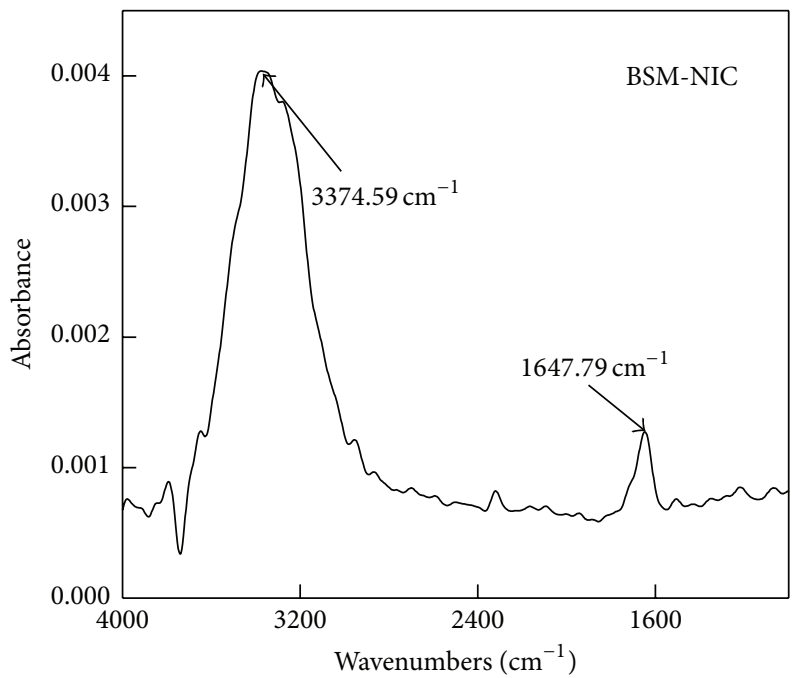

(b)

FIGURE 8: FTIR spectra of BSM in the absence and presence of NIC. $C_{\mathrm{BSM}}=9.52 \times 10^{-5} \mathrm{M}, C_{\mathrm{NIC}}=2.49 \times 10^{-4} \mathrm{M}$.

factors, the vibration frequency or the absorption intensity of these characteristic absorption peaks will be changed, which could demonstrate the ligand interacts with protein and induces conformational changes in the secondary structure of protein [36]. There are three typical absorption bands in the midinfrared region for protein: the first region $\left(\sim 3300 \mathrm{~cm}^{-1}\right)$ refers to the stretching resonance of $\mathrm{NH}[37,38]$; the second one $\left(1700 \sim 1600 \mathrm{~cm}^{-1}\right)$ is caused by $\mathrm{C}=\mathrm{O}$ stretching vibration of amide I band [36]; the last region $\left(1600 \sim 1500 \mathrm{~cm}^{-1}\right)$ involves $\mathrm{N}-\mathrm{H}$ bending vibration and $\mathrm{C}-\mathrm{N}$ stretching vibration of the amide II band [39]. Due to the superior sensitivity of amide I band, it has been more widely selected to study the changes in the protein secondary structure [40].

As shown in Figure 8, the stretching resonance of $\mathrm{NH}$ $\left(3368.55 \mathrm{~cm}^{-1}\right)$ and $\mathrm{C}=\mathrm{O}$ stretching vibration of amide $\mathrm{I}$ band $\left(1645.49 \mathrm{~cm}^{-1}\right)$ in BSM are clear to be observed. After adding NIC, blue shifts of wavenumbers occurred in both of the above bands: the stretching resonance of $\mathrm{NH}$ shifted to $3374.59 \mathrm{~cm}^{-1}$ and $\mathrm{C}=\mathrm{O}$ stretching vibration of amide I band shifted to $1647.79 \mathrm{~cm}^{-1}$. Therefore, the addition of NIC changed the original network of hydrogen bonds, namely, affected the spatial structure of BSM, which could explain the interaction between NIC and BSM from another perspective.

\section{Conclusions}

The binding of NIC to BSM was confirmed by NMR, fluorescence, and FT-IR approaches. NMR spectra disclosed the existence of interaction between NIC and BSM and demonstrated that it was mainly contributed by the pyrrolidyl ring of NIC with the molecule of BSM. Fluorescence spectra also proved the interaction from another perspective; namely, the fluorescence of BSM could be quenched by NIC. The influence of $\mathrm{pH}$ on the interaction of NIC with BSM was explored to show that different values of $\mathrm{pH}$ corresponded to different interactional strength and quenching mechanisms. When $\mathrm{pH}<7$, the dynamic quenching was performed; while $\mathrm{pH}>7$, the quenching was static with larger quenching constants than those of the former. Synchronous fluorescence, 3D fluorescence, and FTIR spectra indicated that nicotine had effect on the microenvironment of BSM and could lead the polarity around the Trp residue increase. This study can not only help to fill the gaps of research in the interaction between NIC and salivary mucin but also contribute to cognize the impact of NIC on the oral environment and provide theoretical basis for limiting smoking.

\section{Conflict of Interests}

The authors declare that there is no conflict of interests regarding the publication of this paper.

\section{Acknowledgment}

The authors gratefully acknowledge the financial support from China Tobacco Yunnan Industrial Co., Ltd. (Grant no. 2014H1069).

\section{References}

[1] D. J. Thornton, K. Rousseau, and M. A. McGuckin, "Structure and function of the polymeric mucins in airways mucus," Annual Review of Physiology, vol. 70, pp. 459-486, 2008.

[2] J. Dekker, J. W. A. Rossen, H. A. Büller, and A. W. C. Einerhand, "The MUC family: an obituary," Trends in Biochemical Sciences, vol. 27, no. 3, pp. 126-131, 2002.

[3] B. Zappone, N. J. Patil, J. B. Madsen, K. I. Pakkanen, and S. Lee, "Molecular structure and equilibrium forces of bovine submaxillary mucin adsorbed at a solid-liquid interface," Langmuir, vol. 31, no. 15, pp. 4524-4533, 2015. 
[4] J. Sotres, J. B. Madsen, T. Arnebrant, and S. Lee, "Adsorption and nanowear properties of bovine submaxillary mucin films on solid surfaces: influence of solution $\mathrm{pH}$ and substrate hydrophobicity," Journal of Colloid and Interface Science, vol. 428, pp. 242-250, 2014.

[5] M. Lundin, T. Sandberg, K. D. Caldwell, and E. Blomberg, "Comparison of the adsorption kinetics and surface arrangement of 'as received' and purified bovine submaxillary gland mucin (BSM) on hydrophilic surfaces," Journal of Colloid and Interface Science, vol. 336, no. 1, pp. 30-39, 2009.

[6] B. L. Slomiany, V. L. Murty, J. Piotrowski, and A. Slomiany, "Salivary mucins in oral mucosal defense," General Pharmacology: The Vascular System, vol. 27, no. 5, pp. 761-771, 1996.

[7] H. Y. Çelebioğlu, M. Gudjónsdóttir, S. Meier, J. Ø. Duus, S. Lee, and I. S. Chronakis, "Spectroscopic studies of the interactions between $\beta$-lactoglobulin and bovine submaxillary mucin," Food Hydrocolloids, vol. 50, pp. 203-210, 2015.

[8] S. Senapati, S. Das, and S. K. Batra, "Mucin-interacting proteins: from function to therapeutics," Trends in Biochemical Sciences, vol. 35, no. 4, pp. 236-245, 2010.

[9] A. Zalewska, K. Zwierz, K. Zółkowski, and A. Gindzieński, "Structure and biosynthesis of human salivary mucins," Acta Biochimica Polonica, vol. 47, no. 4, pp. 1067-1079, 1999.

[10] J. Kono, H. Miyata, S. Ushijima et al., "Nicotine, alcohol, methamphetamine, and inhalant dependence: a comparison of clinical features with the use of a new clinical evaluation form," Alcohol, vol. 24, no. 2, pp. 99-106, 2001.

[11] A. W. Bruijnzeel and M. S. Gold, "The role of corticotropinreleasing factor-like peptides in cannabis, nicotine, and alcohol dependence," Brain Research Reviews, vol. 49, no. 3, pp. 505-528, 2005.

[12] M. Takano, M. Nagahiro, and R. Yumoto, "Transport mechanism of nicotine in primary cultured alveolar epithelial cells," Journal of Pharmaceutical Sciences, vol. 105, no. 2, pp. 982-988, 2016.

[13] L. Di Bari, S. Ripoli, S. Pradhan, and P. Salvadori, "Interactions between quercetin and warfarin for albumin binding: a new eye on food/drug interference," Chirality, vol. 22, no. 6, pp. 593-596, 2010.

[14] J. Lin, Y. Liu, M. Chen, H. Huang, and L. Song, "Investigation on the binding activities of citalopram with human and bovine serum albumins," Journal of Luminescence, vol. 146, pp. 114-122, 2014.

[15] X. Zhou, Q. Yang, X. Xie et al., "NMR, multi-spectroscopic and molecular modeling approach to investigate the complexes between C.I. Acid Orange 7 and human serum albumin in vitro," Dyes and Pigments, vol. 92, no. 3, pp. 1100-1107, 2012.

[16] P. Zhu, G. Zhang, Y. Ma, Y. Zhang, H. Miao, and Y. Wu, "Study of DNA interactions with bifenthrin by spectroscopic techniques and molecular modeling," Spectrochimica Acta Part A: Molecular and Biomolecular Spectroscopy, vol. 112, pp. 7-14, 2013.

[17] F. Dangkoob, M. R. Housaindokht, A. Asoodeh, O. Rajabi, Z. Rouhbakhsh Zaeri, and A. Verdian Doghaei, "Spectroscopic and molecular modeling study on the separate and simultaneous bindings of alprazolam and fluoxetine hydrochloride to human serum albumin (HSA): with the aim of the drug interactions probing," Spectrochimica Acta Part A: Molecular and Biomolecular Spectroscopy, vol. 137, pp. 1106-1119, 2015.
[18] F. Cui, L. Qin, G. Zhang, Q. Liu, X. Yao, and B. Lei, "Interaction of anthracycline disaccharide with human serum albumin: investigation by fluorescence spectroscopic technique and modeling studies," Journal of Pharmaceutical and Biomedical Analysis, vol. 48, no. 3, pp. 1029-1036, 2008.

[19] J. Li, J. Li, Y. Jiao, and C. Dong, "Spectroscopic analysis and molecular modeling on the interaction of jatrorrhizine with human serum albumin (HSA)," Spectrochimica Acta Part A: Molecular and Biomolecular Spectroscopy, vol. 118, pp. 48-54, 2014.

[20] G. Rabbani, M. J. Khan, A. Ahmad, M. Y. Maskat, and R. H. Khan, "Effect of copper oxide nanoparticles on the conformation and activity of $\beta$-galactosidase," Colloids and Surfaces B: Biointerfaces, vol. 123, pp. 96-105, 2014.

[21] Y. Li, G. Zhang, and M. Tao, "Binding properties of herbicide chlorpropham to DNA: spectroscopic, chemometrics and modeling investigations," Journal of Photochemistry and Photobiology B: Biology, vol. 138, pp. 109-117, 2014.

[22] B. M. Liu, J. Zhang, Y. Liu et al., "Multi-spectroscopic methods investigation on the interaction of tenoxicam with DNA," Luminescence, vol. 30, no. 8, pp. 1313-1317, 2015.

[23] G. Rabbani, E. Ahmad, N. Zaidi, and R. H. Khan, "pH-dependent conformational transitions in conalbumin (Ovotransferrin), a metalloproteinase from hen egg white," Cell Biochemistry and Biophysics, vol. 61, no. 3, pp. 551-560, 2011.

[24] Y.-Z. Zhang, B. Zhou, X.-P. Zhang, P. Huang, C.-H. Li, and Y. Liu, "Interaction of malachite green with bovine serum albumin: determination of the binding mechanism and binding site by spectroscopic methods," Journal of Hazardous Materials, vol. 163, no. 2-3, pp. 1345-1352, 2009.

[25] Y. Cui, Z. Fu, S. Geng, G. Zhang, and F. Cui, "Interaction of one anthraquinone derivative with ctDNA analyzed by spectroscopic and modeling methods," Journal of Fluorescence, vol. 24, no. 5, pp. 1389-1396, 2014.

[26] C.-B. Chen, J. Chen, J. Wang, Y.-Y. Zhu, and J.-H. Shi, “Combined spectroscopic and molecular docking approach to probing binding interactions between lovastatin and calf thymus DNA," Luminescence, vol. 30, no. 7, pp. 1004-1010, 2015.

[27] P. D. Ross and S. Subramanian, "Thermodynamics of protein association reactions: forces contributing to stability," Biochemistry, vol. 20, no. 11, pp. 3096-3102, 1981.

[28] K. Kosno, I. Janik, M. Celuch, J. Mirkowski, J. Kisała, and D. Pogocki, "The role of $\mathrm{pH}$ in the mechanism of $\mathrm{OH}$ radical induced oxidation of nicotine," Israel Journal of Chemistry, vol. 54, no. 3, pp. 302-315, 2014.

[29] M. S. Nair, "Spectroscopic study on the interaction of resveratrol and pterostilbene with human serum albumin," Journal of Photochemistry and Photobiology B: Biology, vol. 149, pp. 58-67, 2015.

[30] B. K. Sahoo, K. S. Ghosh, and S. Dasgupta, "Molecular interactions of isoxazolcurcumin with human serum albumin: spectroscopic and molecular modeling studies," Biopolymers, vol. 91, no. 2, pp. 108-119, 2009.

[31] H.-M. Zhang, Y.-Q. Xu, Q.-H. Zhou, and Y.-Q. Wang, "Investigation of the interaction between chlorophenols and lysozyme in solution," Journal of Photochemistry and Photobiology B: Biology, vol. 104, no. 3, pp. 405-413, 2011.

[32] D. Li, T. Zhang, C. Xu, and B. Ji, "Effect of $\mathrm{pH}$ on the interaction of baicalein with lysozyme by spectroscopic approaches," Journal of Photochemistry and Photobiology B: Biology, vol. 104, no. 3, pp. 414-424, 2011. 
[33] Q. Wang, J. He, D. Wu, J. Wang, J. Yan, and H. Li, “Interaction of $\alpha$-cyperone with human serum albumin: determination of the binding site by using Discovery Studio and via spectroscopic methods," Journal of Luminescence, vol. 164, pp. 81-85, 2015.

[34] S. Ghosh, N. K. Pandey, S. Sen, D. R. Tripathy, and S. Dasgupta, "Binding of hen egg white lysozyme fibrils with nucleic acids," Journal of Photochemistry and Photobiology B: Biology, vol. 127, pp. 52-60, 2013.

[35] G. Zhang and Y. Ma, "Mechanistic and conformational studies on the interaction of food dye amaranth with human serum albumin by multispectroscopic methods," Food Chemistry, vol. 136, no. 2, pp. 442-448, 2013.

[36] X. Peng, X. Wang, W. Qi, R. Su, and Z. He, "Affinity of rosmarinic acid to human serum albumin and its effect on protein conformation stability," Food Chemistry, vol. 192, pp. 178-187, 2016.

[37] C. Y. Panicker, H. T. Varghese, L. Ushakumari et al., "FT-IR, FT-Raman, SERS spectra and computational calculations of 4-ethyl-N-(2'-hydroxy-5' -nitrophenyl)benzamide," Journal of Raman Spectroscopy, vol. 41, no. 4, pp. 381-390, 2010.

[38] F. A. M. Al-Omary, A. Raj, K. Raju et al., "Spectroscopic investigation (FT-IR, FT-Raman), HOMO-LUMO, NBO analysis and molecular docking study of 2-[(4-chlorobenzyl)sulfanyl]-4-(2-methylpropyl)-6-[3-trifluoromethyl)-anilino]pyrimidine-5-carbonitrile, a potential chemotherapeutic agent," Spectrochimica Acta A: Molecular and Biomolecular Spectroscopy, vol. 136, pp. 520-533, 2015.

[39] J.-H. Tang, G.-B. Liang, C.-Z. Zheng, and N. Lian, "Investigation on the binding behavior of ellagic acid to human serum albumin in aqueous solution," Journal of Solution Chemistry, vol. 42, no. 1, pp. 226-238, 2013.

[40] Y. Li, W. He, Y. Dong, F. Sheng, and Z. Hu, "Human serum albumin interaction with formononetin studied using fluorescence anisotropy, FT-IR spectroscopy, and molecular modeling methods," Bioorganic \& Medicinal Chemistry, vol. 14, no. 5, pp. 1431-1436, 2006. 

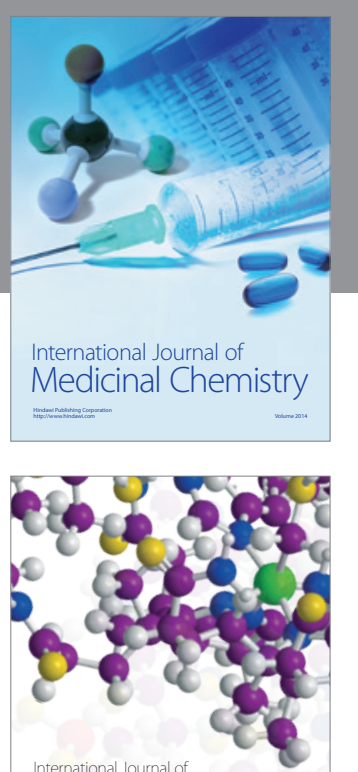

Carbohydrate Chemistry

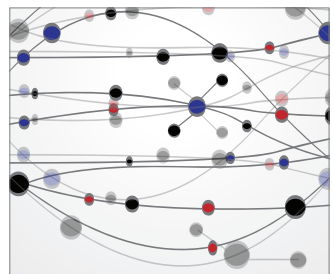

The Scientific World Journal
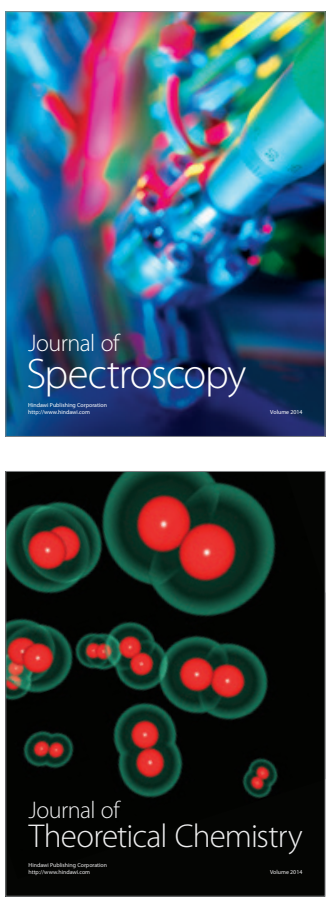
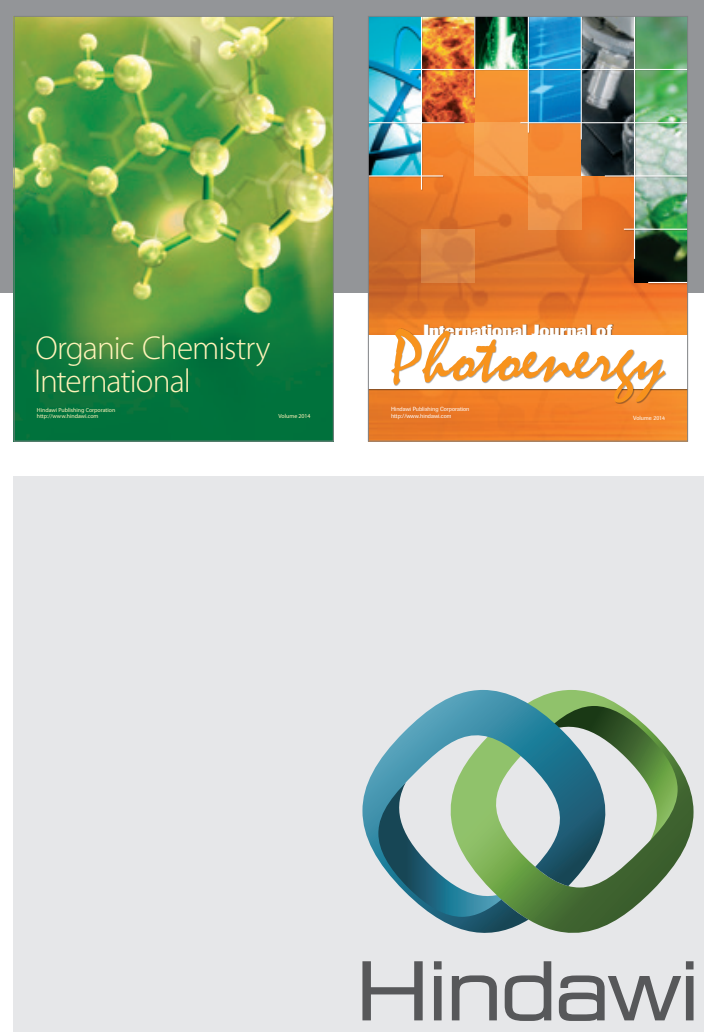

Submit your manuscripts at

http://www.hindawi.com

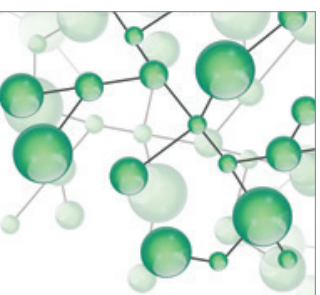

International Journal of

Inorganic Chemistry

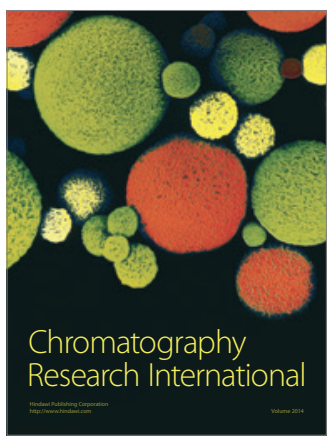

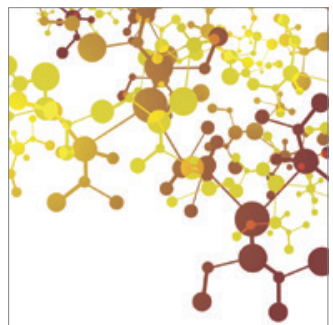

Applied Chemistry
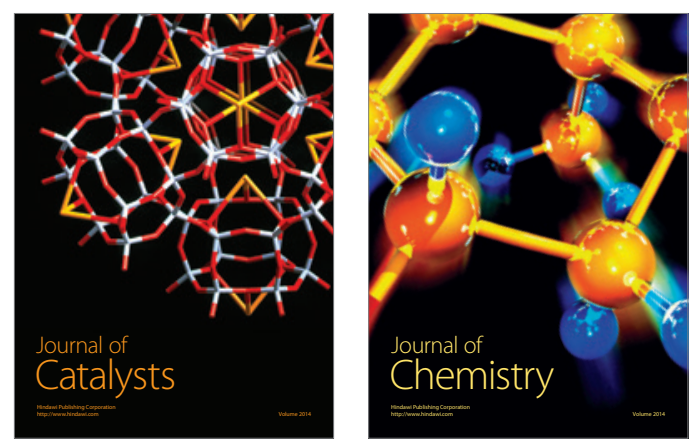
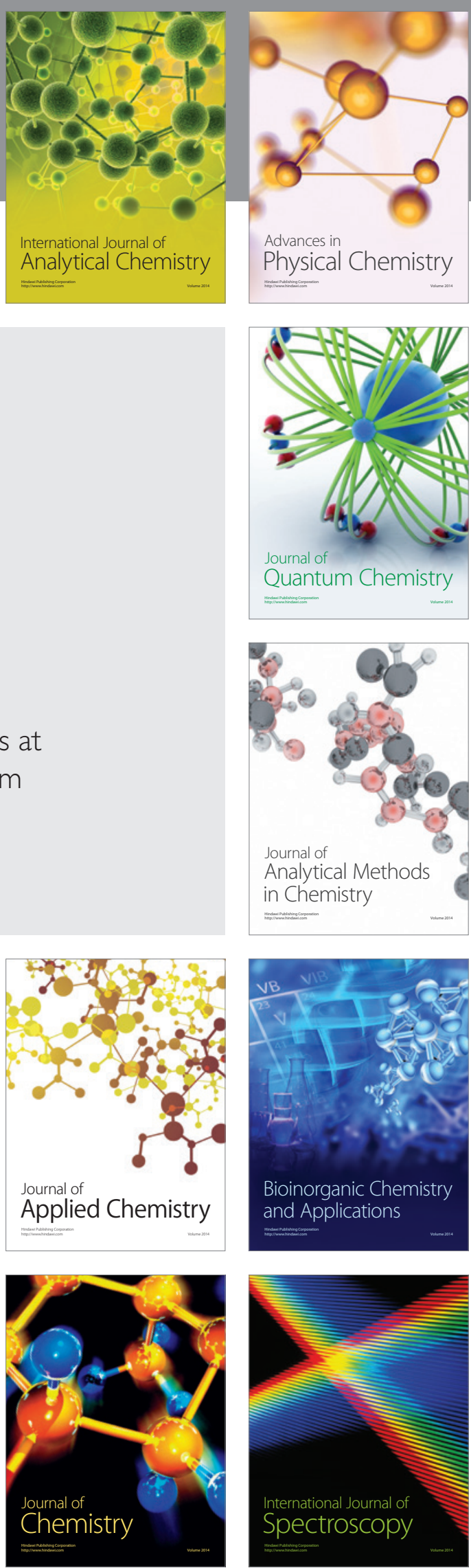